\title{
Ultrasonic Thermometer Sticking Mitigation Assessment
}

\section{August 2021}

Joshua Daw

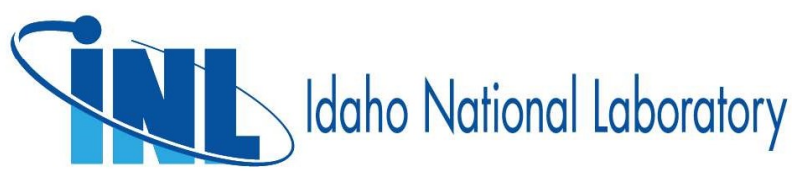




\section{DISCLAIMER}

This information was prepared as an account of work sponsored by an agency of the U.S. Government. Neither the U.S. Government nor any agency thereof, nor any of their employees, makes any warranty, expressed or implied, or assumes any legal liability or responsibility for the accuracy, completeness, or usefulness, of any information, apparatus, product, or process disclosed, or represents that its use would not infringe privately owned rights. References herein to any specific commercial product, process, or service by trade name, trade mark, manufacturer, or otherwise, does not necessarily constitute or imply its endorsement, recommendation, or favoring by the U.S. Government or any agency thereof. The views and opinions of authors expressed herein do not necessarily state or reflect those of the U.S. Government or any agency thereof. 


\title{
Ultrasonic Thermometer Sticking Mitigation Assessment
}

\author{
Joshua Daw
}

August 2021

\section{Idaho National Laboratory \\ Measurement Sciences Laboratory Idaho Falls, Idaho 83415}

http://www.inl.gov

Prepared for the U.S. Department of Energy Office of Nuclear Energy Under DOE Idaho Operations Office

Contract DE-AC07-05ID14517 
Page intentionally left blank 


\begin{abstract}
Ultrasonic thermometers (UTs) carry the potential to improve on current technologies for very high temperature measurements. One issue limiting their adoption is the diffusion bond formation that occurs between the acoustic waveguide used as the sensor, and its surroundings (in some cases, a protective sheath). Several potential methods for reducing this diffusion bonding (known as sticking) have been identified. Prototype UTs were fabricated and tested to high temperatures in order to evaluate these methods. Several showed promise for lowtemperature use. The most promising option was 3-D-printed ceramic spacers.
\end{abstract}


Page intentionally left blank 


\section{CONTENTS}

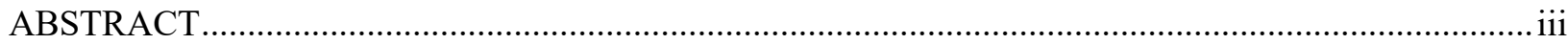

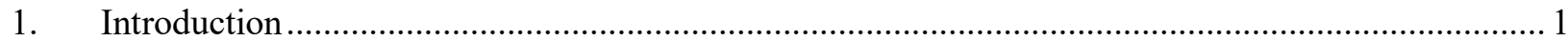

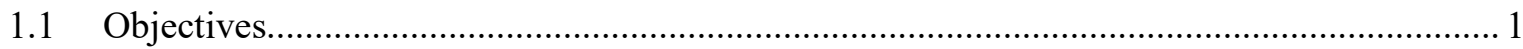

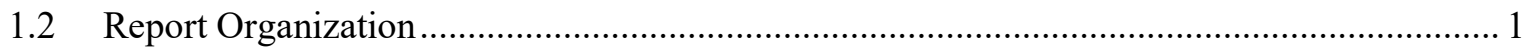

2. Ultrasonic Thermometer Configurations Tested ........................................................................ 2

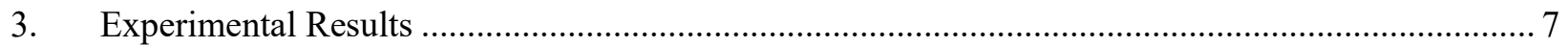

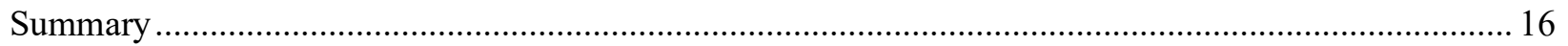

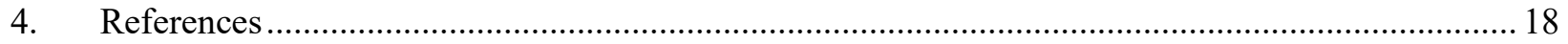

\section{FIGURES}

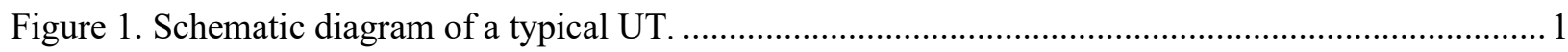

Figure 2. Reference UT design featuring no sticking mitigation..............................................................2

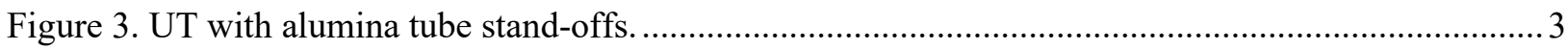

Figure 4. UT with a laser micro-welded bump stand-off.............................................................. 4

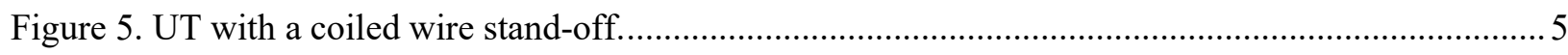

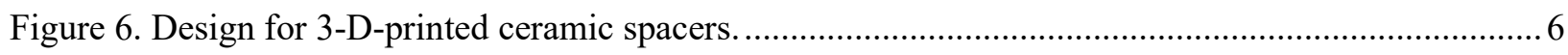

Figure 7. UT with 3-D-printed alumina spacers in the heated section............................................... 7

Figure 8. High-temperature vacuum furnace used for testing....................................................... 8

Figure 9. Waveforms recorded for the reference (i.e., no stand-off) Zircaloy-4 UT. .............................. 8

Figure 10. Closeup of waveforms recorded for the reference Zircaloy-4 UT, evidencing onset of

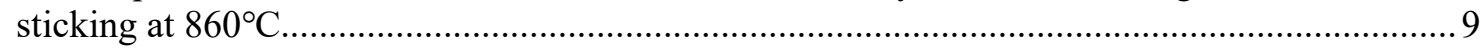

Figure 11. Waveforms recorded for the Zircaloy-4 UT with the alumina tube stand-off.........................9

Figure 12. Waveforms recorded for the Zircaloy-4 UT with micro-welded reflector-type standoffs.

Figure 13. Closeup of waveforms recorded for the Zircaloy-4 UT with micro-welded reflectortype stand-offs, evidencing onset of sticking at $720^{\circ} \mathrm{C}$.

Figure 14. X-ray image of welded bump stand-off and weld-induced bending of the waveguide............. 11

Figure 15. Waveforms recorded for the Zircaloy-4 UT with the W-5\% Re coil stand-off....................... 12

Figure 16. Waveforms recorded for the reference (i.e., no stand-off) Mo UT with an Nb sheath.............. 12

Figure 17. Waveforms recorded for the Mo UT with an Nb sheath and W-5\% Re coil stand-off, showing apparent onset of sticking at $1650^{\circ} \mathrm{C}$.

Figure 18. Waveforms recorded for the Mo UT with an $\mathrm{Nb}$ sheath and alumina tube stand-offs, showing apparent onset of sticking at $1900^{\circ} \mathrm{C}$ 
Figure 19. Waveforms recorded for the Mo UT with the Mo sheath and W-5\% Re coil stand-off, showing apparent onset of sticking at $1500^{\circ} \mathrm{C}$

Figure 20. Waveforms recorded for the Mo UT with an Nb sheath and 3-D-printed alumina spacers.

Figure 21. Closeup of waveforms recorded for the Mo UT with an $\mathrm{Nb}$ sheath and 3-D-printed alumina spacers, showing that melting of the spacers occurs at $\sim 2030^{\circ} \mathrm{C}$. 


\section{ACRONYMS}

UT Ultrasonic thermometers 
Page intentionally left blank 


\section{Introduction}

Ultrasonic thermometry carries the potential to improve upon temperature sensors currently used for in-core temperature measurements [1]. Ultrasonic thermometers (UTs) operate on the principle that the speed at which sound travels through a material (acoustic velocity) depends on the temperature of that material. Temperature may be derived by creating a short acoustic pulse within the sensor and then measuring the time delay of acoustic reflections generated at acoustic discontinuities along the length of the sensor. Typically, these discontinuities are created by machining notches into the sensor rod. UTs can be made to have very small diameters while still maintaining a high level of durability, because the sensor simply consists of a small-diameter metallic rod or wire (although a sheath may be required) [2]. Also, no electrical insulation is needed in the sensor. Electrical insulation, which is required for thermocouples and resistance thermometers, can degrade when subjected to high temperatures $\left(>1800^{\circ} \mathrm{C}\right)$, resulting in shunting errors. UT temperature measurements can even be taken at near the melting point of the sensor material, enabling the monitoring of temperatures potentially in excess of $3000^{\circ} \mathrm{C}$ via the use of a tungsten waveguide [3]. The primary appeal of UTs is their potential for enabling real-time, in-core measurement of a temperature profile, using a single multi-segment sensor. Figure 1Figure 1 shows a typical design for a multi-segment UT, with all the key components identified.

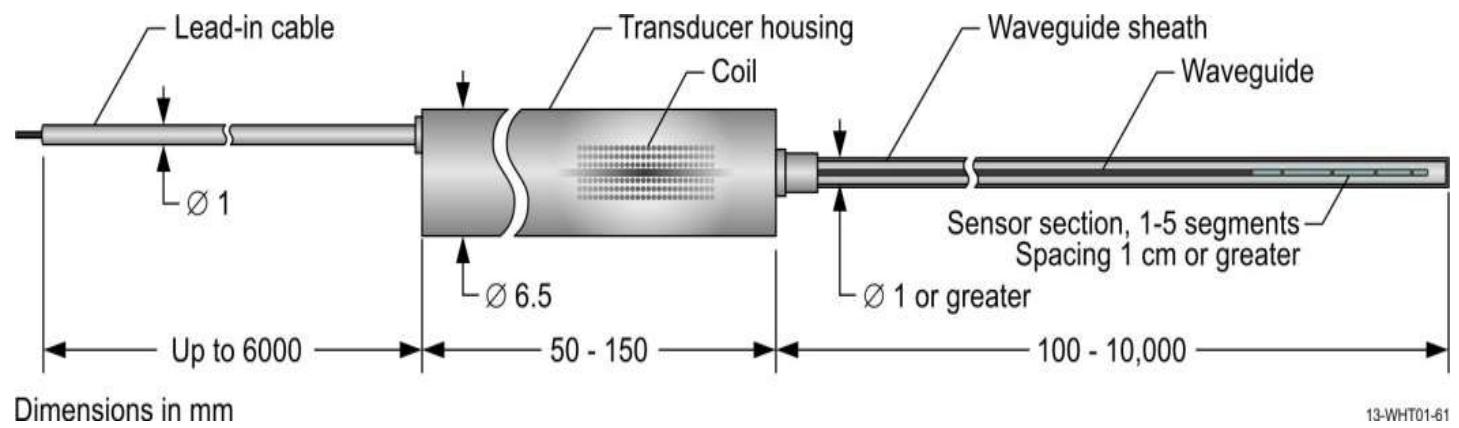

Figure 1. Schematic diagram of a typical UT.

The current UT design uses an inductive coil to generate ultrasonic waves in a magnetostrictive alloy, which is welded to a metallic sensor waveguide, and to sense the vibrations from the reflected sound waves.

Prior research into the development of UTs [3-9] indicates that high-temperature diffusion bonding (also called "sticking") is a persistent issue that continues to limit the adoption of this technology for temperature measurement applications at over $\sim 1800-2000^{\circ} \mathrm{C}$, depending on the materials used for the waveguide, protective sheath, etc.

\subsection{Objectives}

This work seeks to identify a better way to mitigate the effects of diffusion bonding between UT components, by developing newer mitigation methods and updating prior attempts with newer fabrication methods. Test UTs were created using several different material combinations that each employed various anti-sticking strategies, and these combinations were tested to high temperature in a vacuum furnace in order to compare their effectiveness.

\subsection{Report Organization}

Section 2 of this report describes the UTs that were tested. Section 3 presents and discusses the results of the testing. Section 4 summarizes the report and discusses future work. 


\section{Ultrasonic Thermometer Configurations Tested}

Based on results of prior testing [11], in which Zircaloy waveguides experienced sticking at relatively low temperatures, the first set of prototype UTs were fabricated with Zircaloy-4 waveguides and zirconium-702 sheaths. The results of testing these UTs were then used to down-select mitigation candidates for use in higher temperature UTs. These higher temperature UTs were fabricated with molybdenum (Mo) waveguides and either Mo or niobium $(\mathrm{Nb})$ sheaths.

The initial test UT for each material combination was a reference design that lacked any sort of sticking mitigation. An x-ray image of the waveguide within the sheath is shown in Figure 2. It is clear from the figure that contact occurs between the waveguide and sheath. In general, the wires used as waveguides are never truly straight, but have some amount of curvature. Even if the waveguide was perfectly straight, incidental contact would still occur. But with the curvature, contact is inevitable, and some amount of contact force will be present.

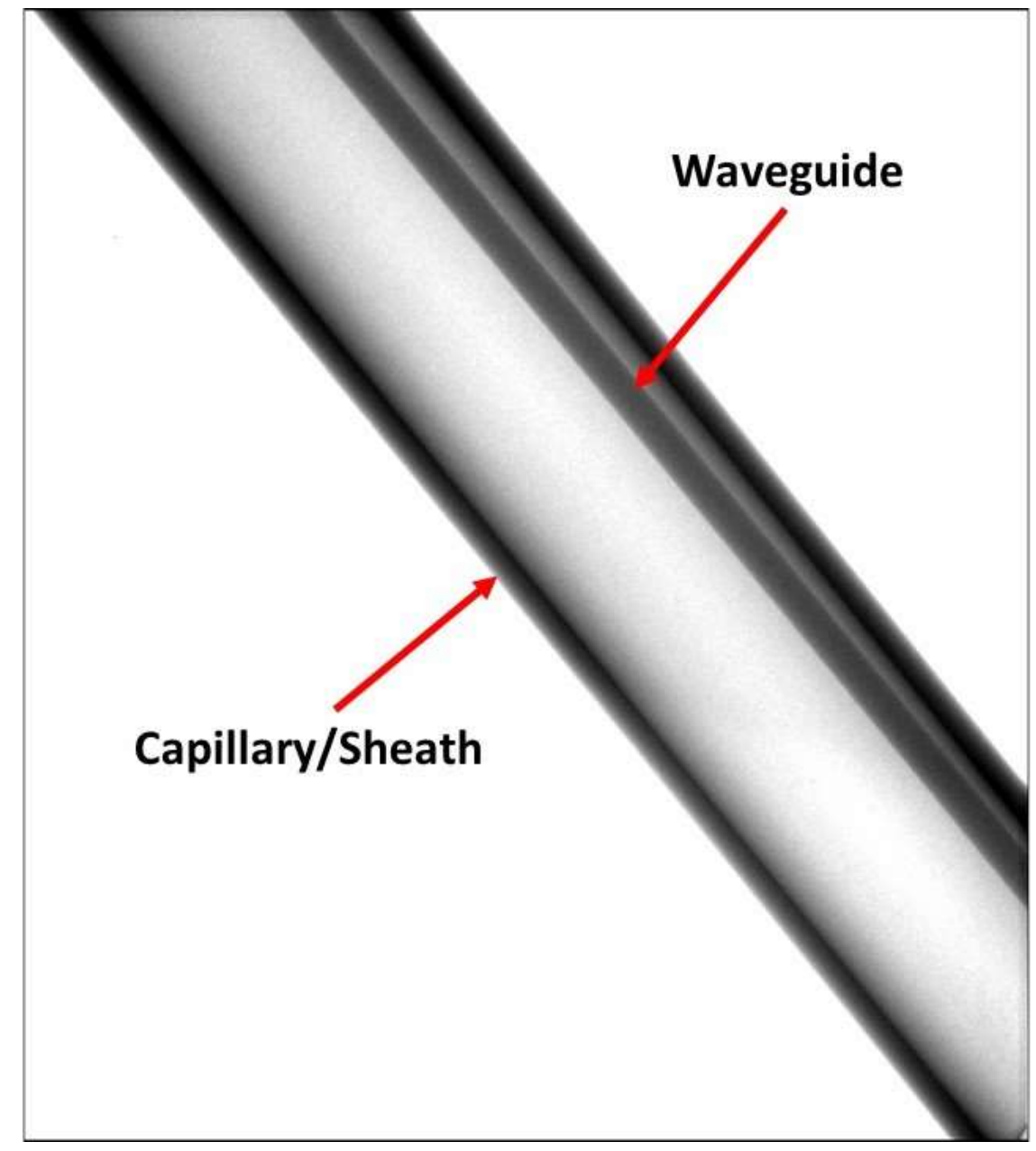

Figure 2. Reference UT design featuring no sticking mitigation.

The second configuration used ceramic tubing (aluminum oxide) as a diffusion barrier between the waveguide and sheath. Alumina's melting point of $2072^{\circ} \mathrm{C}$ limits its use for very high-temperature applications (i.e., those necessitating an Mo waveguide). Alumina was used for comparing the performance of 3-D-printed alumina spacers (described later). Ceramic diffusion barriers had already been tested, and with mixed results [6]. They generally failed at high temperatures, whether due to softening of the ceramic and the subsequent binding of the waveguide as the ceramic relocated, or to 
sublimation of the ceramic and the binding of the waveguide, with the vapor resolidifying in cooler parts of the UT. Figure 3 shows an X-ray image of a UT whose waveguide is centered by alumina tubes (barely visible due to the low density).

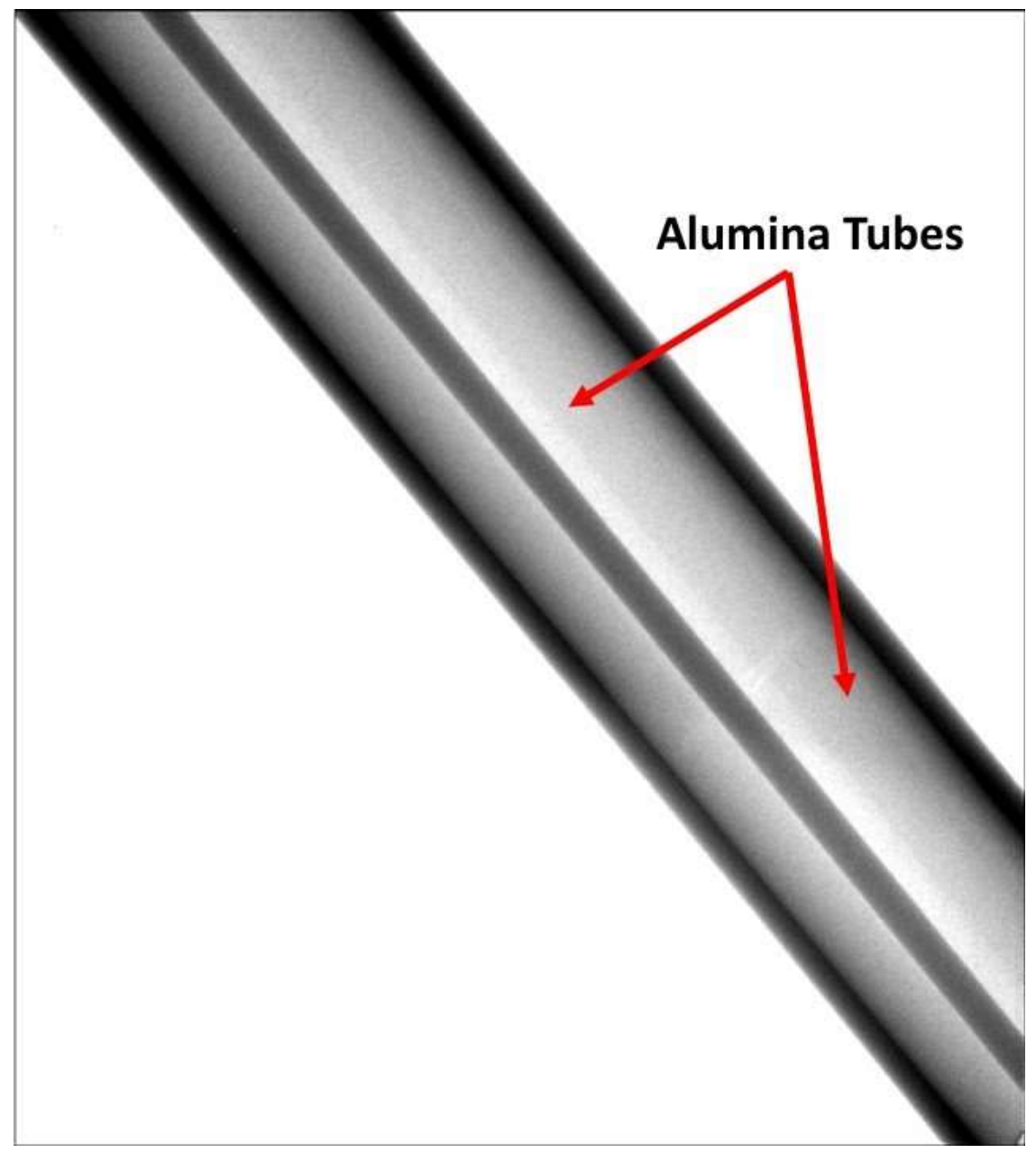

Figure 3. UT with alumina tube stand-offs.

The third type of UT that was tested uses stand-offs formed by laser welding small pieces of wire to the waveguide to form bumps. The wire used was of the same material as the waveguide. This type of stand-off had also been previously tested [6]. The results of previous tests showed that the presence of the stand-offs actually increased the likelihood of sticking, due to increased contact pressure between the sheath and the stand-offs. The development of smaller-diameter waveguide UTs, along with advances in laser welding technology, warrant revisiting this method, as the area of contact between the waveguide and the stand-offs can be minimized, reducing the acoustic coupling between the two. The stand-offs also act as reflectors - another attractive point, since they are necessary for multi-point measurements. Figure 4 shows an x-ray image of a UT with laser-welded stand-offs. 


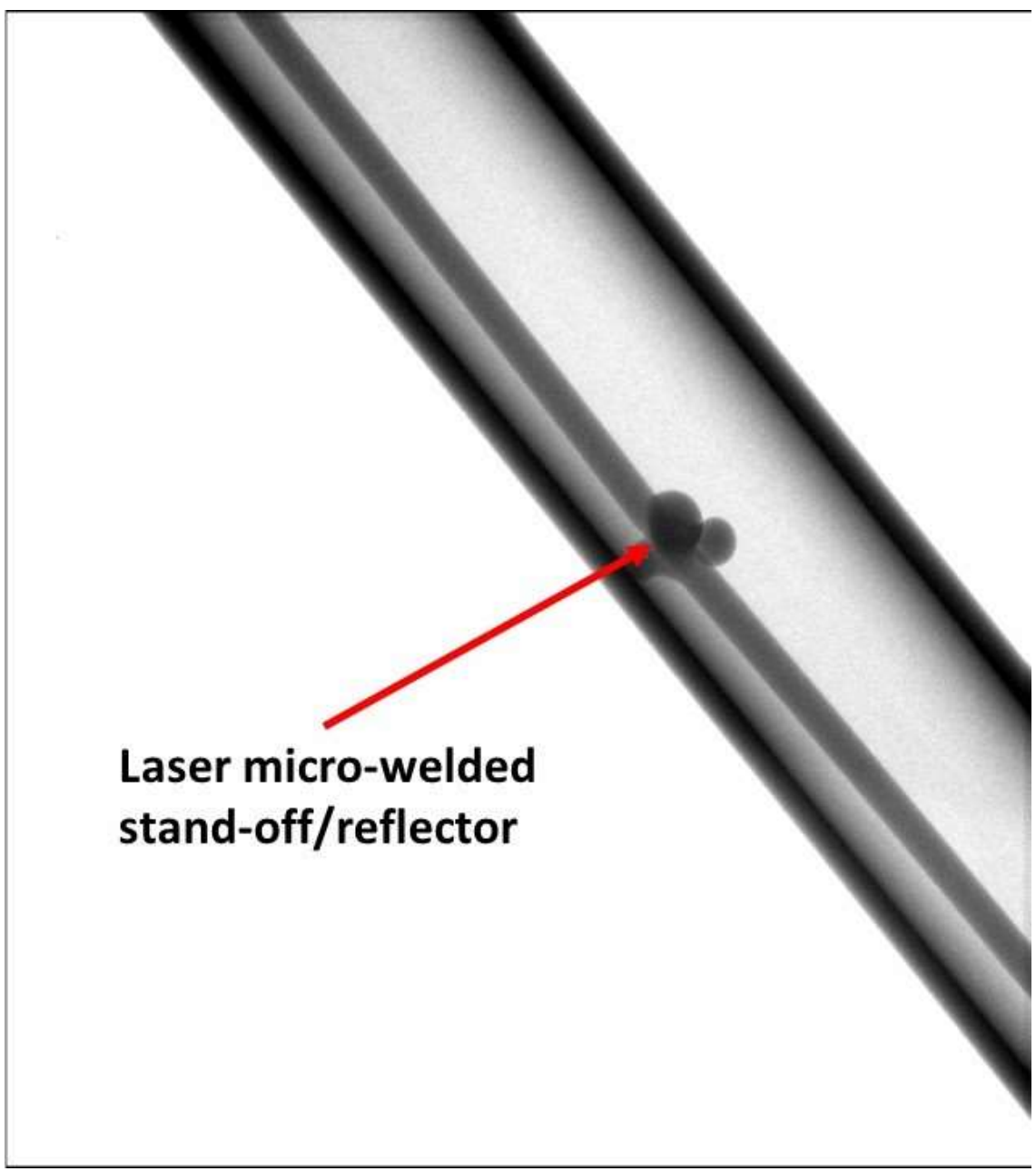

Figure 4. UT with a laser micro-welded bump stand-off.

The fourth type of UT that was tested uses a coil/spring formed from a small-diameter metallic wire and utilized as a stand-off. As with the welded stand-offs, the small points of contact between the waveguide, stand-off, and sheath could generate negative effects due to contact pressure. A $0.23-\mathrm{mm}$ diameter W-5\% Re thermocouple wire was used for the coil. This wire has a very high melting temperature (nearly as high as for pure tungsten, but with improved ductility). Figure 5 shows an x-ray image of a UT with a coil separating the waveguide from the sheath. 


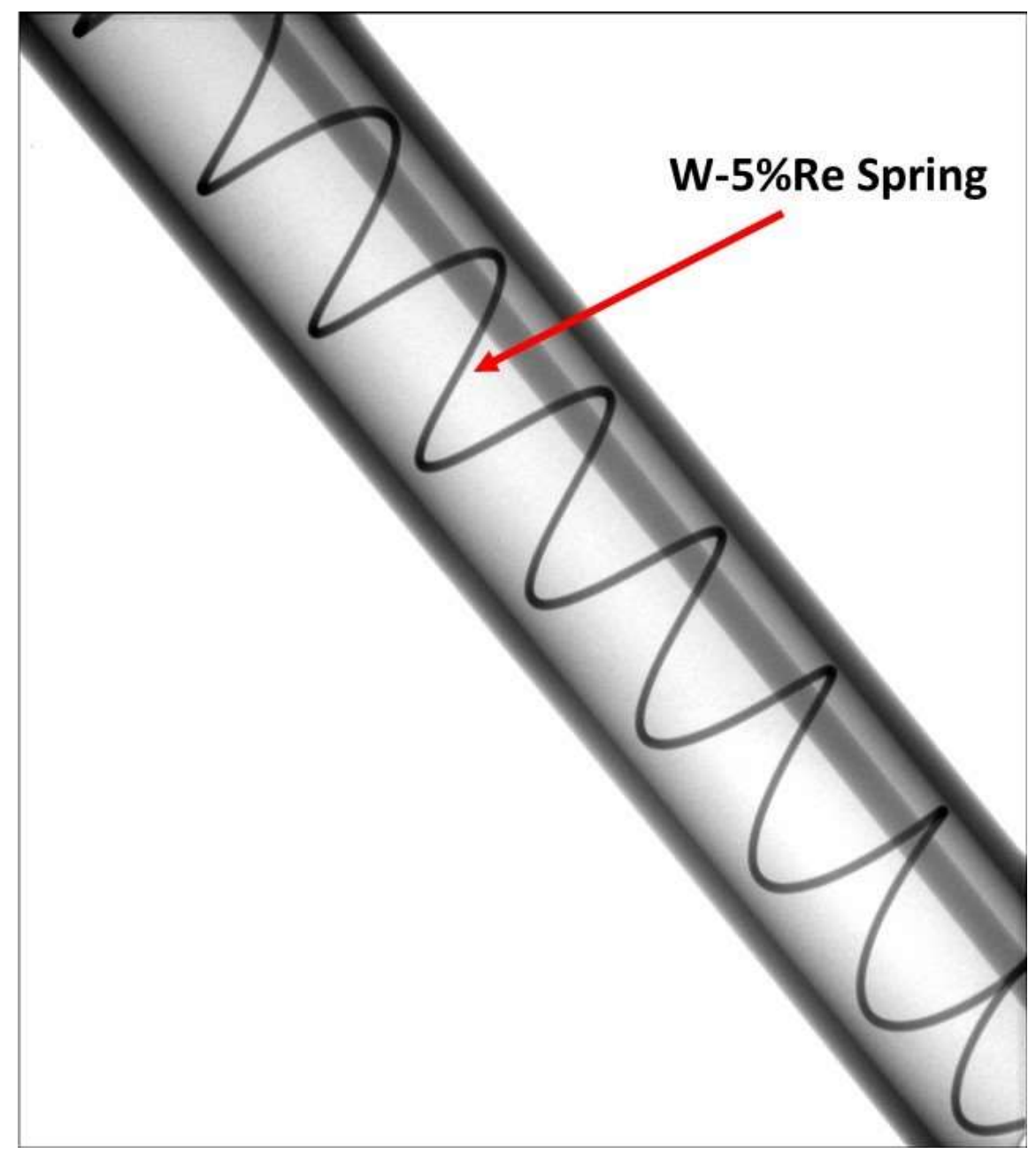

Figure 5. UT with a coiled wire stand-off.

The fifth UT configuration used 3-D-printed ceramic tubing (aluminum oxide). At the time of these tests, both alumina and zirconia were available for 3-D printing. Although zirconia has a much higher melting temperature (i.e., $2700^{\circ} \mathrm{C}$ ), alumina was selected, as zirconia is known to react with Mo at high temperatures [9]. Note that 3-D-printed spacers were only used in the Mo/Mo UT, as only enough were available to create a single prototype. Figure 6 shows a drawing of the spacer design, along with a photograph of the 3-D printed spacer (the designed features were at the limit of the current capabilities of digital light processing printing technology). Figure 7 shows an $\mathrm{x}$-ray image of a UT whose waveguide is centered by the printed spacers. The spacers consist of a thin-walled tube capped with an integrated "washer" to minimize contact with the waveguide and center it within the sheath. 


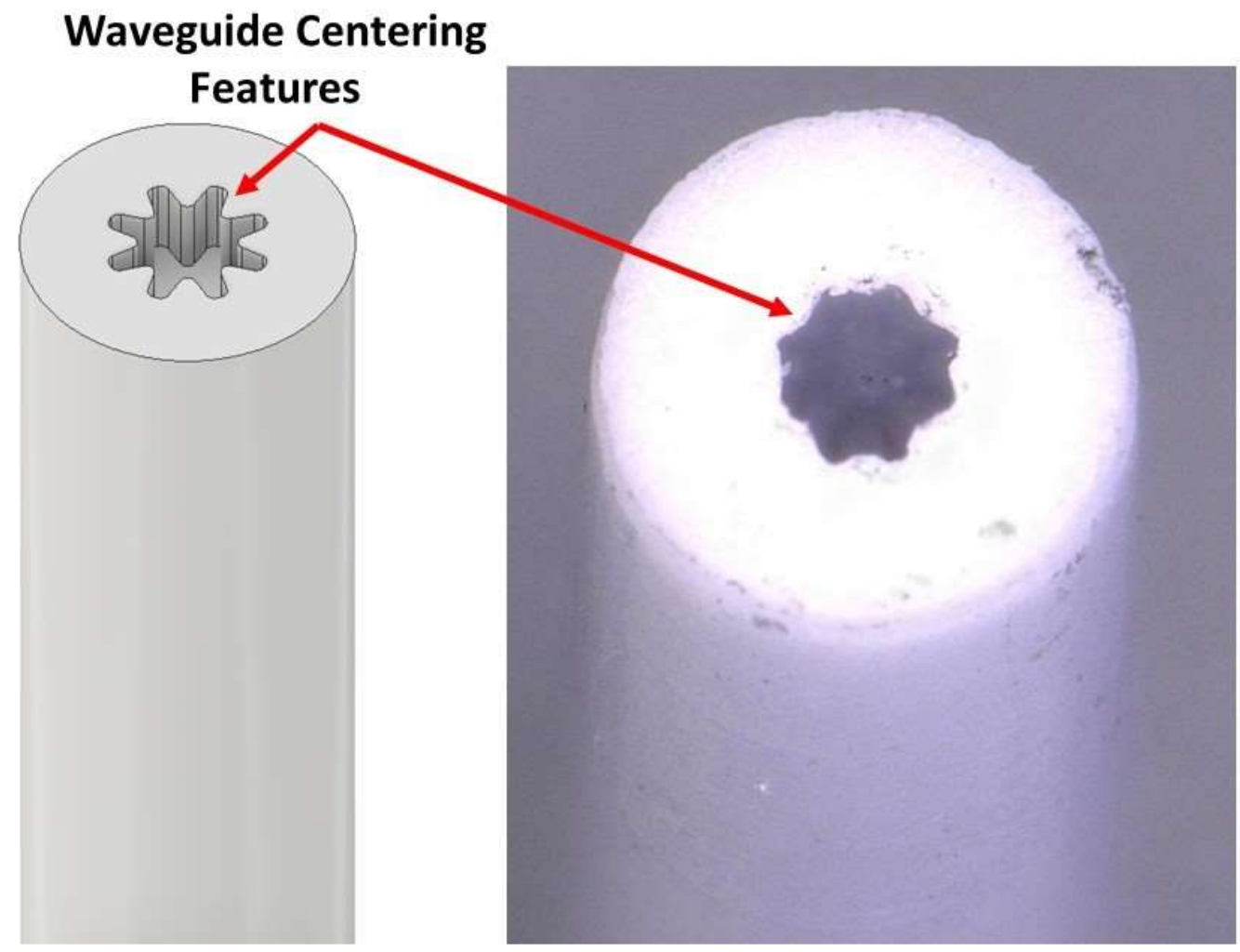

\section{CAD Drawing}

Printed Part

Figure 6. Design for 3-D-printed ceramic spacers. 


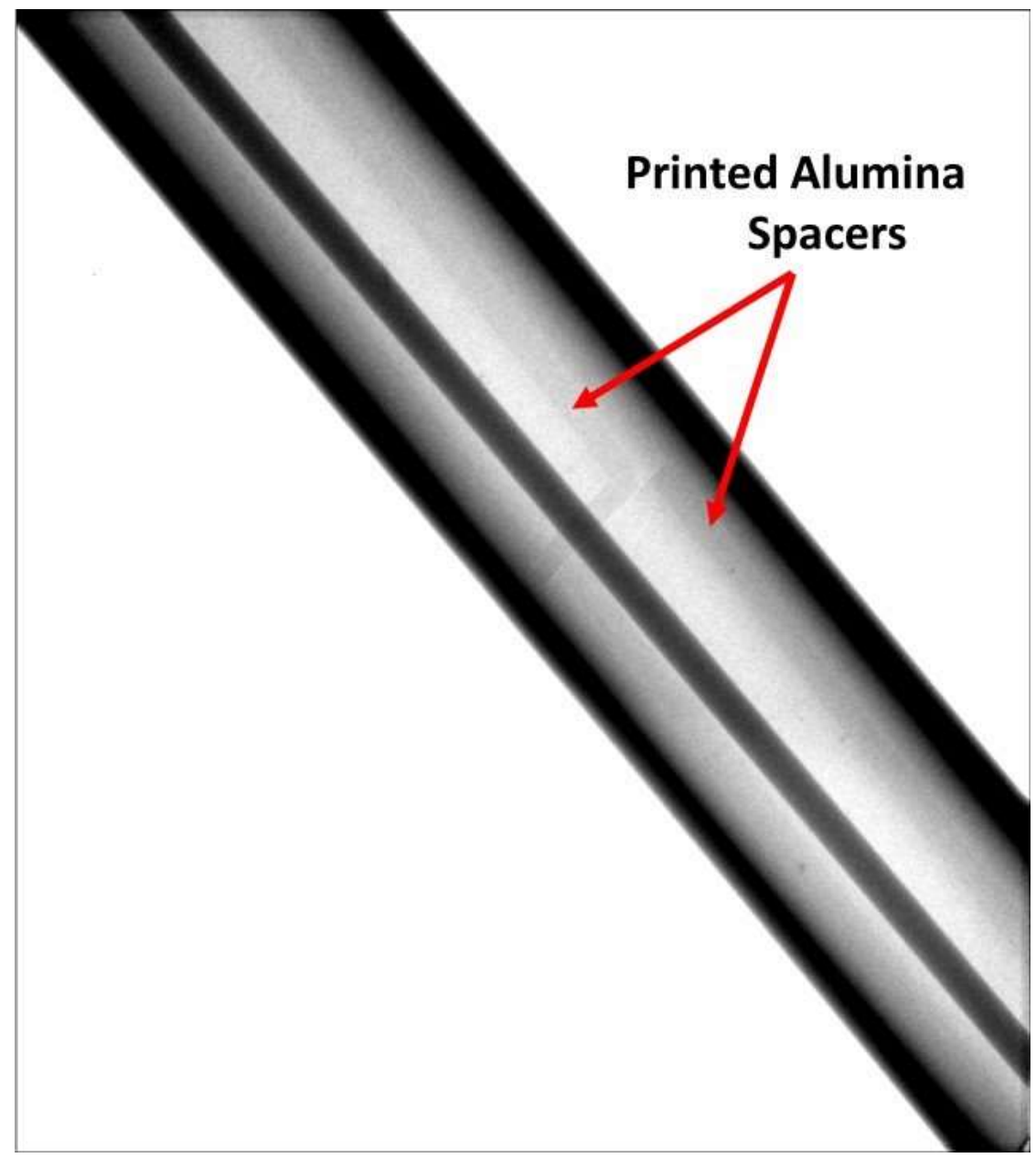

Figure 7. UT with 3-D-printed alumina spacers in the heated section.

\section{Experimental Results}

The prototype UTs were tested in a high-temperature vacuum furnace (see Figure 8). Each UT was tested individually, due to the limitations of furnace feedthroughs and data acquisition channels. The pulse/echo signals were monitored in real-time to identify the temperature at which onset of sticking occurs. Temperatures were monitored using the furnace control thermocouple (for below $1000^{\circ} \mathrm{C}$ ) and pyrometer (for over $1000^{\circ} \mathrm{C}$ ). 


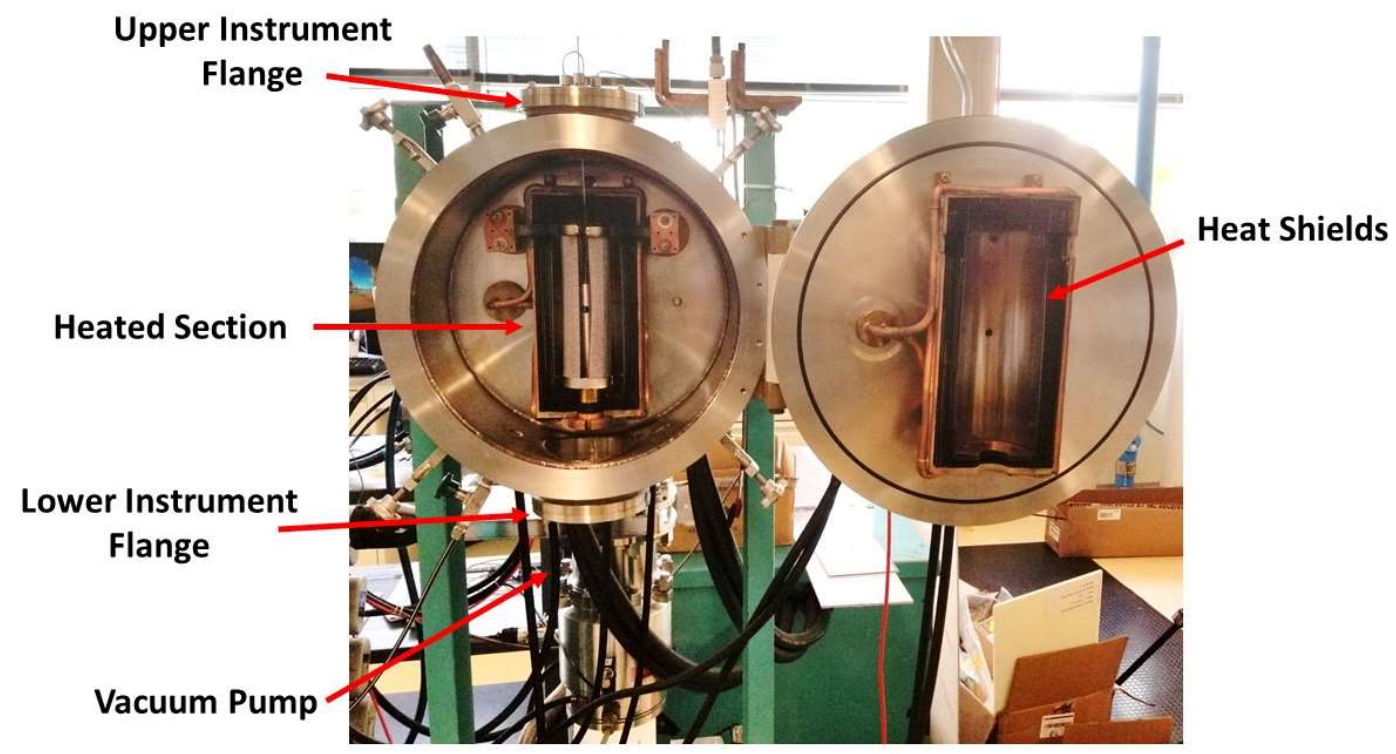

Figure 8. High-temperature vacuum furnace used for testing.

Figure 9 shows waveforms collected at various temperatures for the reference (i.e., no stand-off) Zircaloy-4 UT. It should be noted that changes to the initial waveform (i.e., those occurring prior to 100 $\mu \mathrm{s}$ ), as well as some of the increased noise, resulted from boosting the signal gain to offset temperatureinduced attenuation. The rightward shift in the reflected signal is due to decreases in acoustic velocity during heating. In the waveform collected at $950^{\circ} \mathrm{C}$, the new signal artifact at $\sim 200 \mu$ s is indicative of sticking. Figure 10 gives a closer view of the waveforms collected at both 690 and $860^{\circ} \mathrm{C}$. The waveform collected at $860^{\circ} \mathrm{C}$ shows the earliest formation of this extra signal artifact. Thus, onset of sticking is considered to have occurred at $\sim 860^{\circ} \mathrm{C}$.

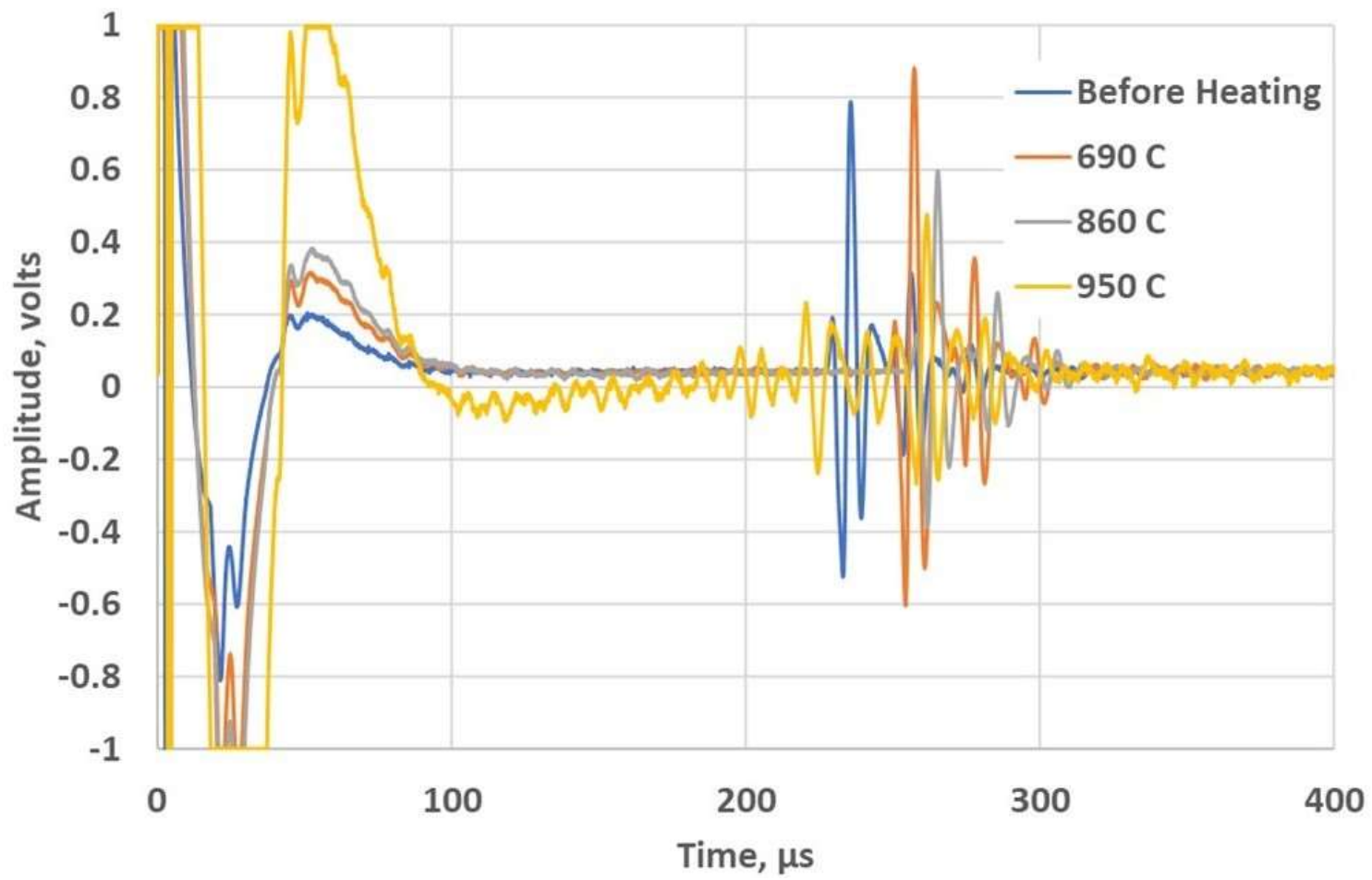

Figure 9. Waveforms recorded for the reference (i.e., no stand-off) Zircaloy-4 UT. 


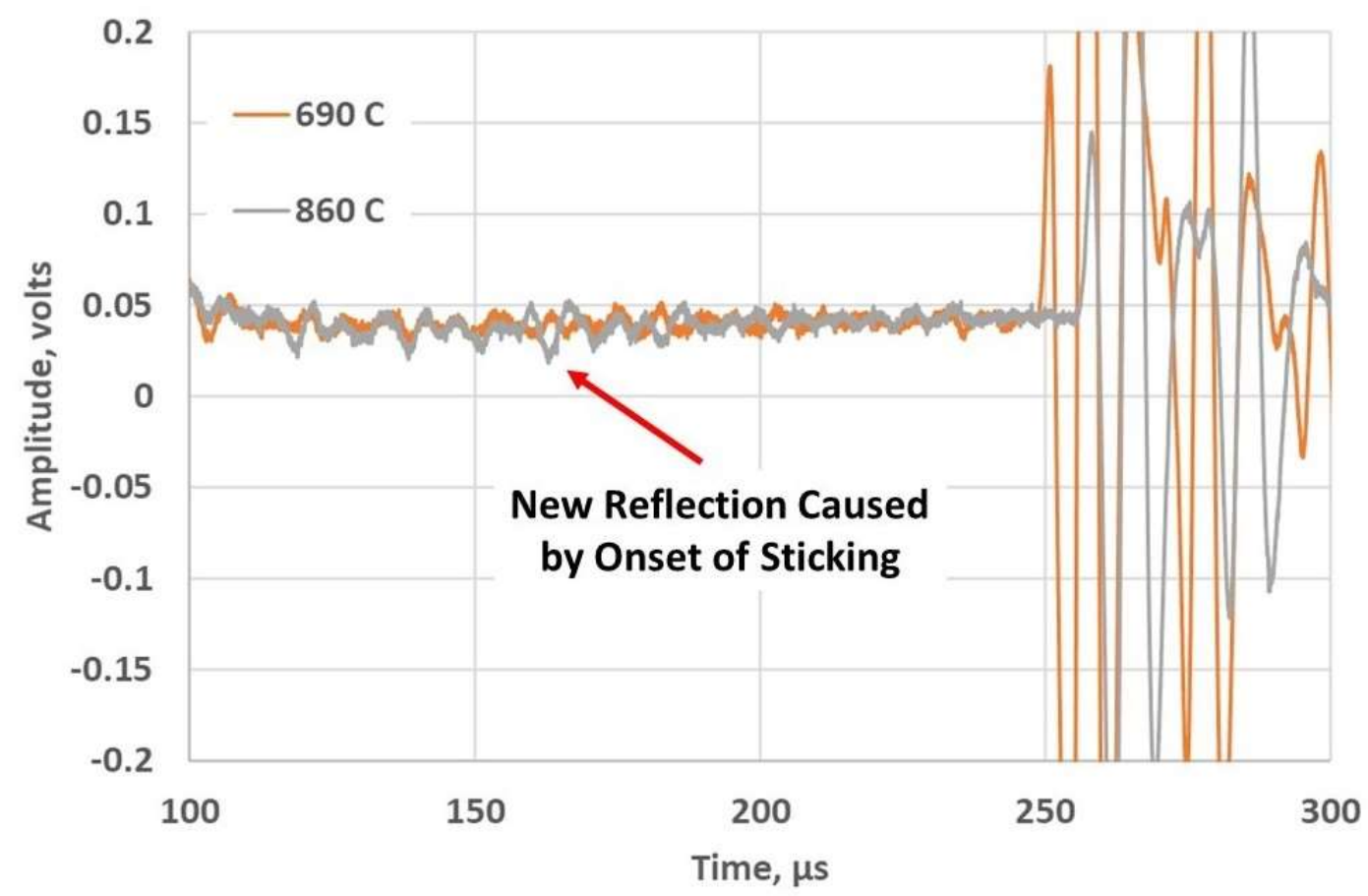

Figure 10. Closeup of waveforms recorded for the reference Zircaloy-4 UT, evidencing onset of sticking at $860^{\circ} \mathrm{C}$.

Figure 11 shows waveforms collected at various temperatures for the Zircaloy-4 UT in which alumina tubes are used as spacers. The small amounts of noise in the lead-in signal are caused by slight stresses at the joints between each alumina spacer, where the waveguide is slightly pinched. This UT was heated well past the point of total signal attenuation yet showed no indication of sticking.

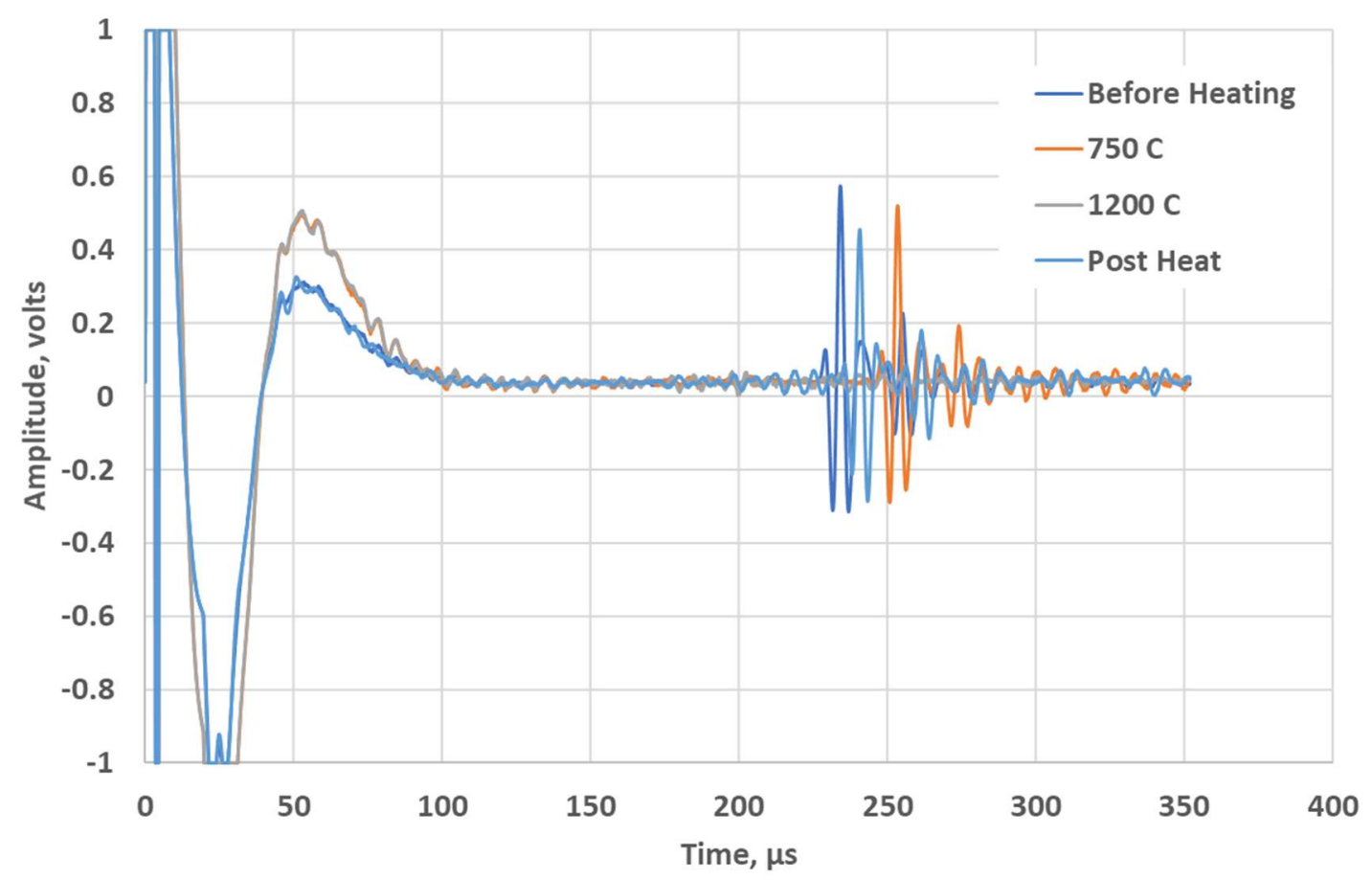

Figure 11. Waveforms recorded for the Zircaloy-4 UT with the alumina tube stand-off. 
Figure 12 shows waveforms collected at various temperatures for the Zircaloy-4 UT with welded reflector stand-offs. As with the previous UT, this prototype was heated beyond the point of total signal attenuation. Figure 13 gives a closeup of the waveforms collected at room temperature and at $720^{\circ} \mathrm{C}$. A new signal artifact is observed at $720^{\circ} \mathrm{C}$, representing the onset of sticking. Although this seems to indicate that the effects observed by Arave [6] are the cause, such is not actually the case. The new sticking reflection is adjacent to the first reflector. A second x-ray image, shown in Figure 14, explains this. Welding tends to cause stresses in small-diameter wires, which then form bends at the weld points and are more likely to contact the sheath and to do so with some force, increasing the likelihood of diffusion bond formation. From a practical standpoint, even if the welded stand-offs were effective, the number of usable reflectors of this type is limited, as acoustic waves will reflect from them as the waves pass the reflectors in each direction. Thus, each subsequent reflector must reflect increasingly more energy in order for the reflected waves to reach the transducer. This effect of having multiple reflections also leads to a ring-down effect and an overlap in the received signal, making the signal difficult to interpret. Thus, the number of reflectors must be kept small (i.e., 1-10) for signal clarity and positioned close together for anti-sticking effectiveness.

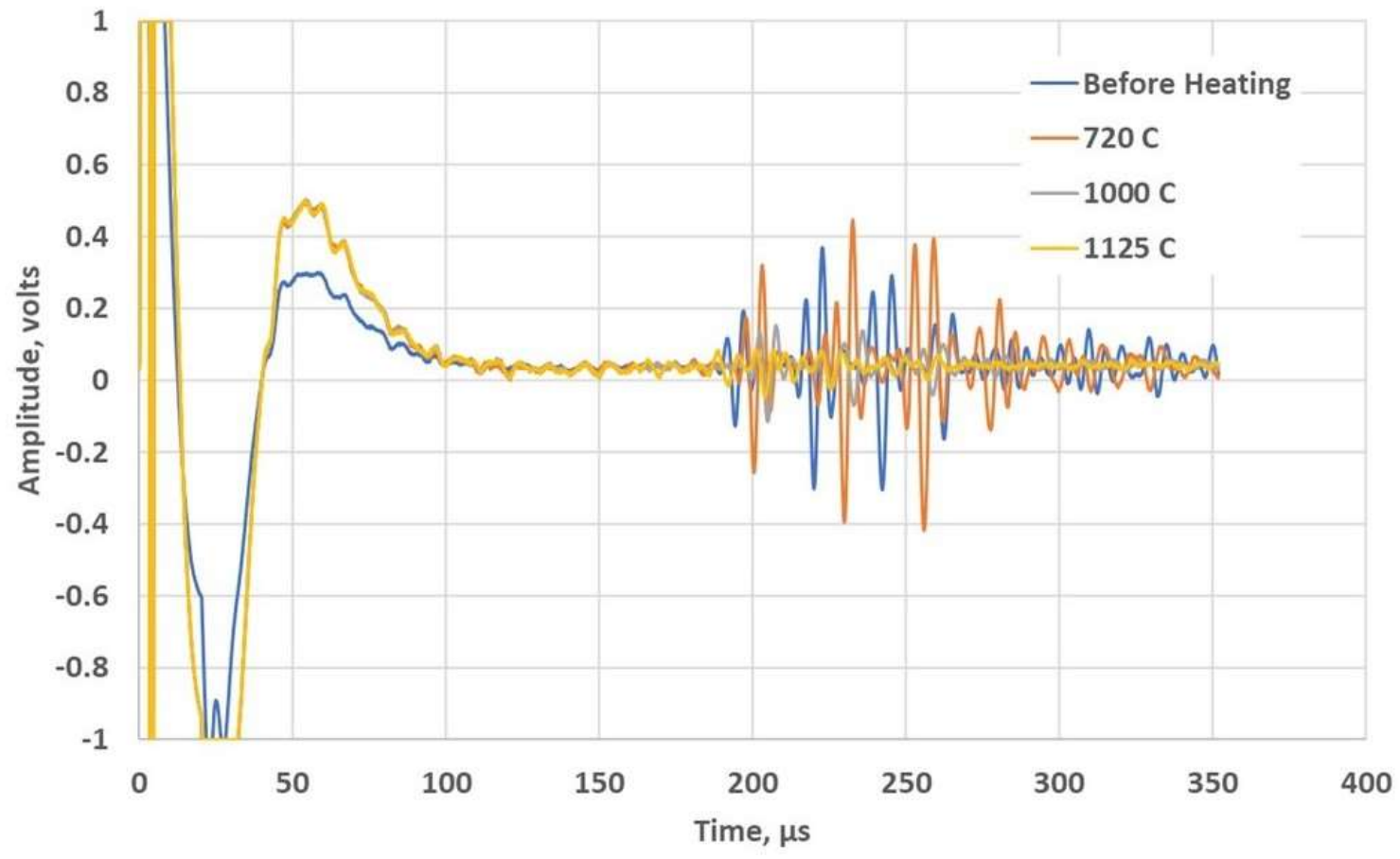

Figure 12. Waveforms recorded for the Zircaloy-4 UT with micro-welded reflector-type stand-offs. 


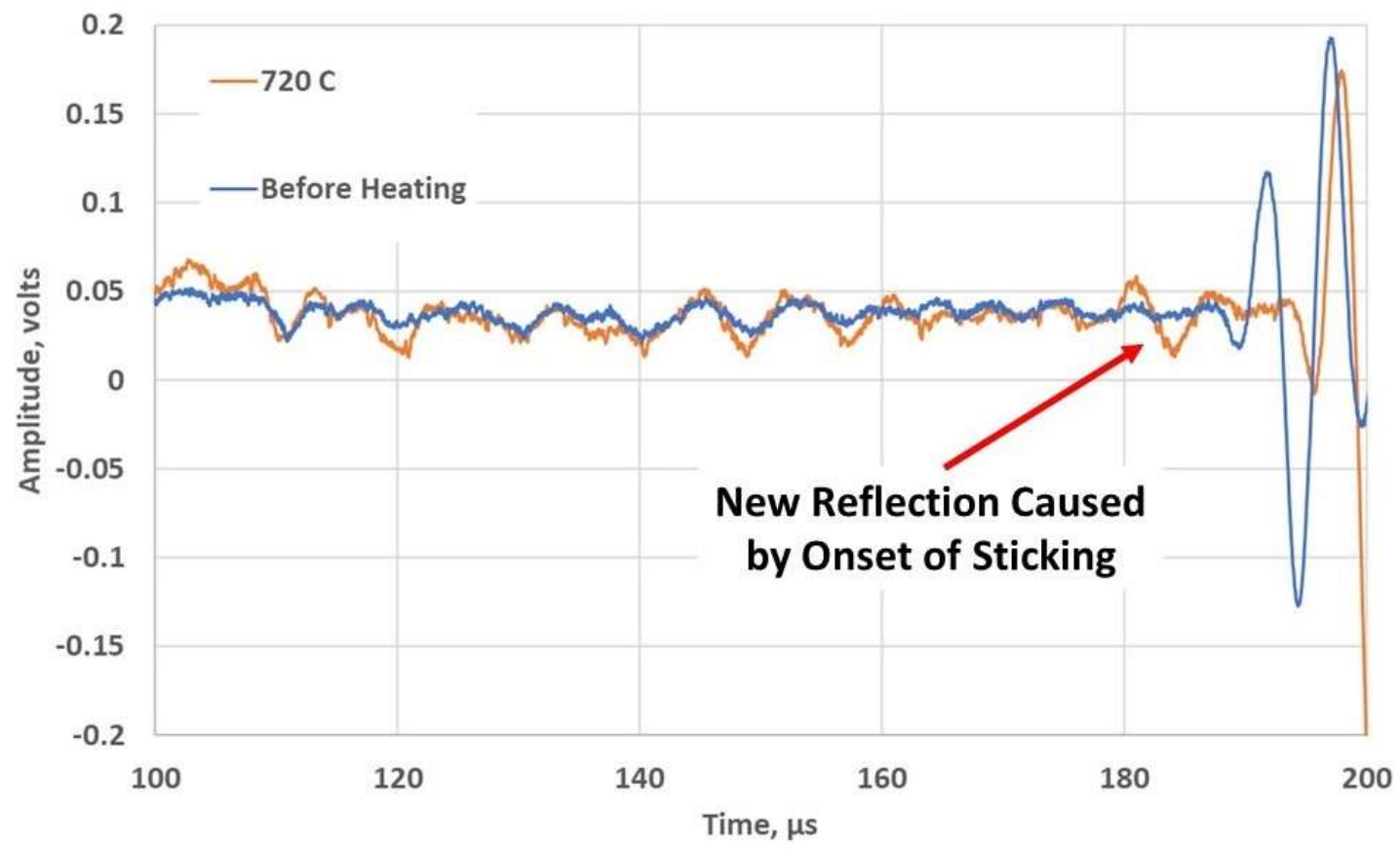

Figure 13. Closeup of waveforms recorded for the Zircaloy-4 UT with micro-welded reflector-type standoffs, evidencing onset of sticking at $720^{\circ} \mathrm{C}$.

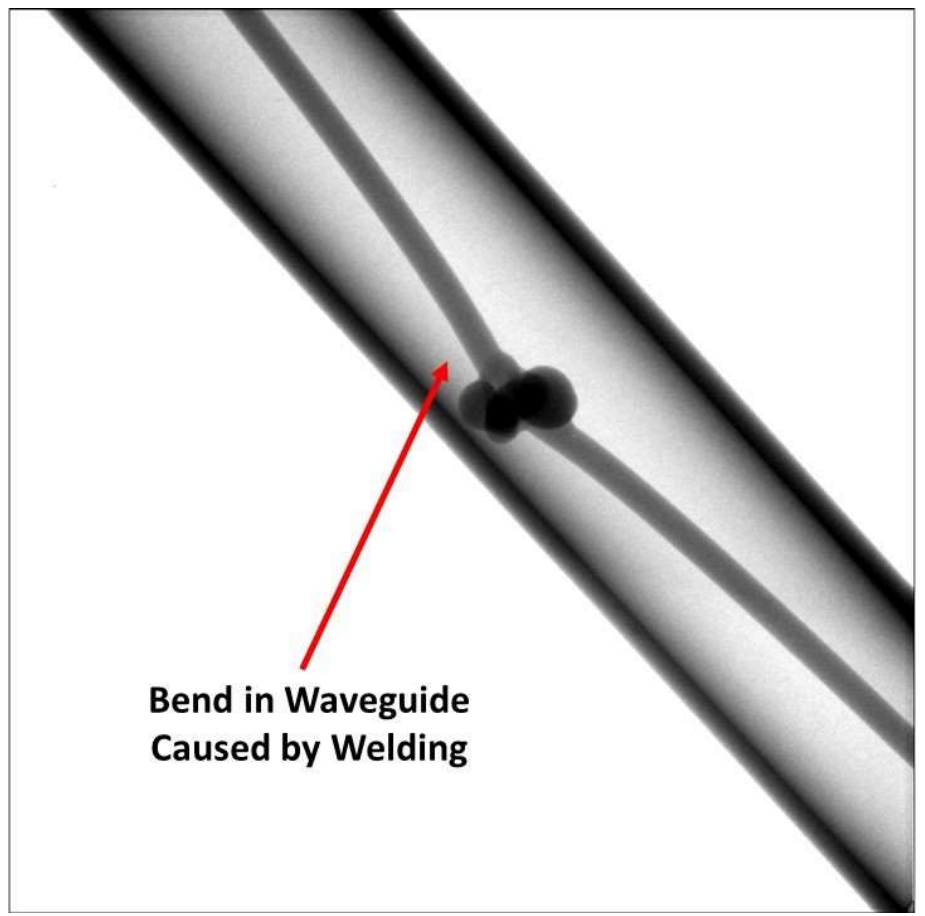

Figure 14. X-ray image of welded bump stand-off and weld-induced bending of the waveguide.

Figure 15 shows waveforms collected at various temperatures for the Zircaloy-4 UT with the W-5\% Re coil stand-off. This prototype was heated to the point of total signal attenuation. There were no signs of sticking at any temperature. The shift in reflection position between the "Before Heating" and "Post Heat" waveforms (both collected at room temperature) was due to annealing of the waveguide at high temperature. 


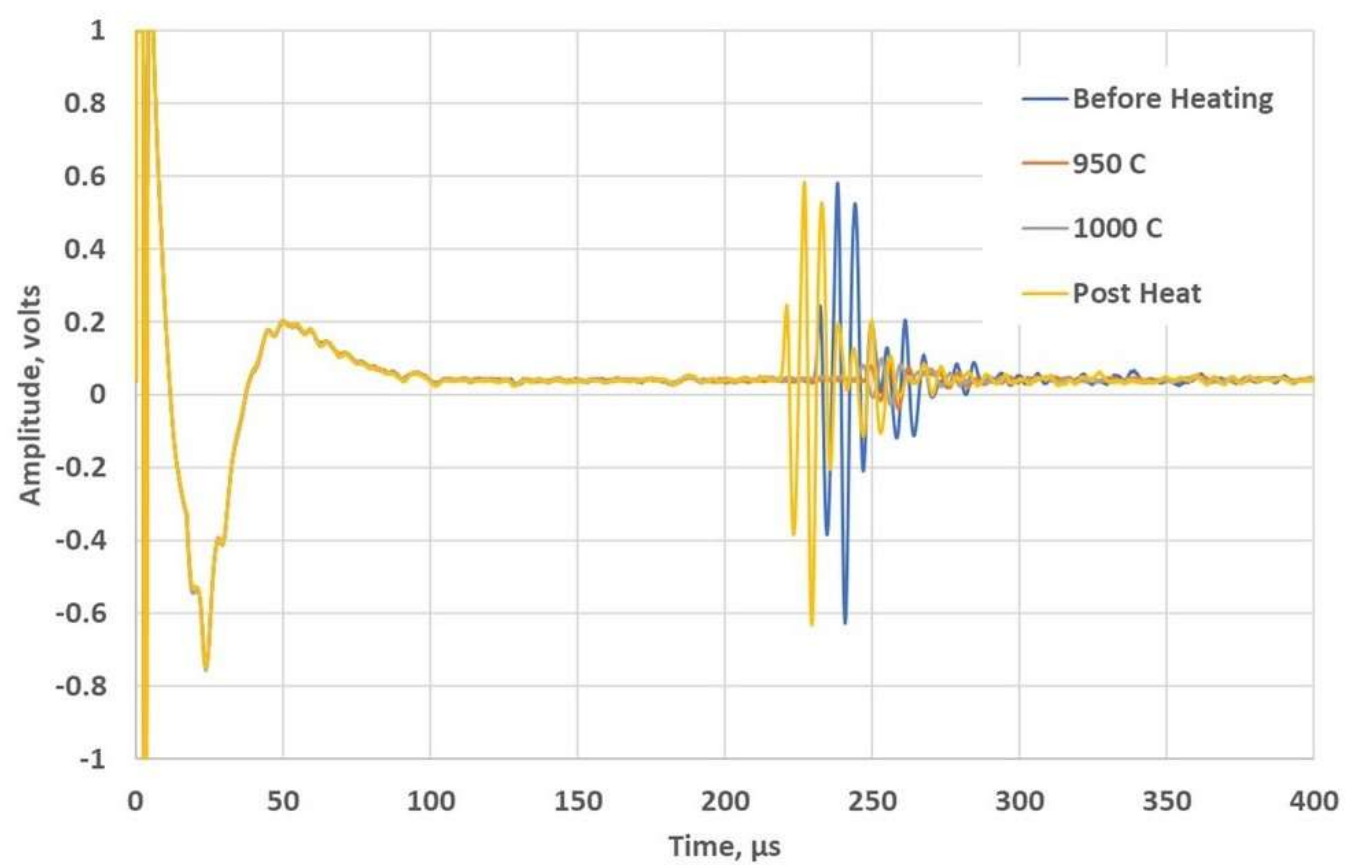

Figure 15. Waveforms recorded for the Zircaloy-4 UT with the W-5\% Re coil stand-off.

The second group of UT prototypes that were tested utilized Mo waveguides and $\mathrm{Nb}$ sheaths. This represents an overall increase in the potential operating temperature, but with high potential for diffusion bonding between the dissimilar metals.

The first Mo/Nb UT tested was, again, a reference model featuring no sticking mitigation whatsoever. Figure 16 shows waveforms collected at room temperature (both before and after testing) and at $1250^{\circ} \mathrm{C}$. Rapid onset of sticking was observed at $1250^{\circ} \mathrm{C}$.

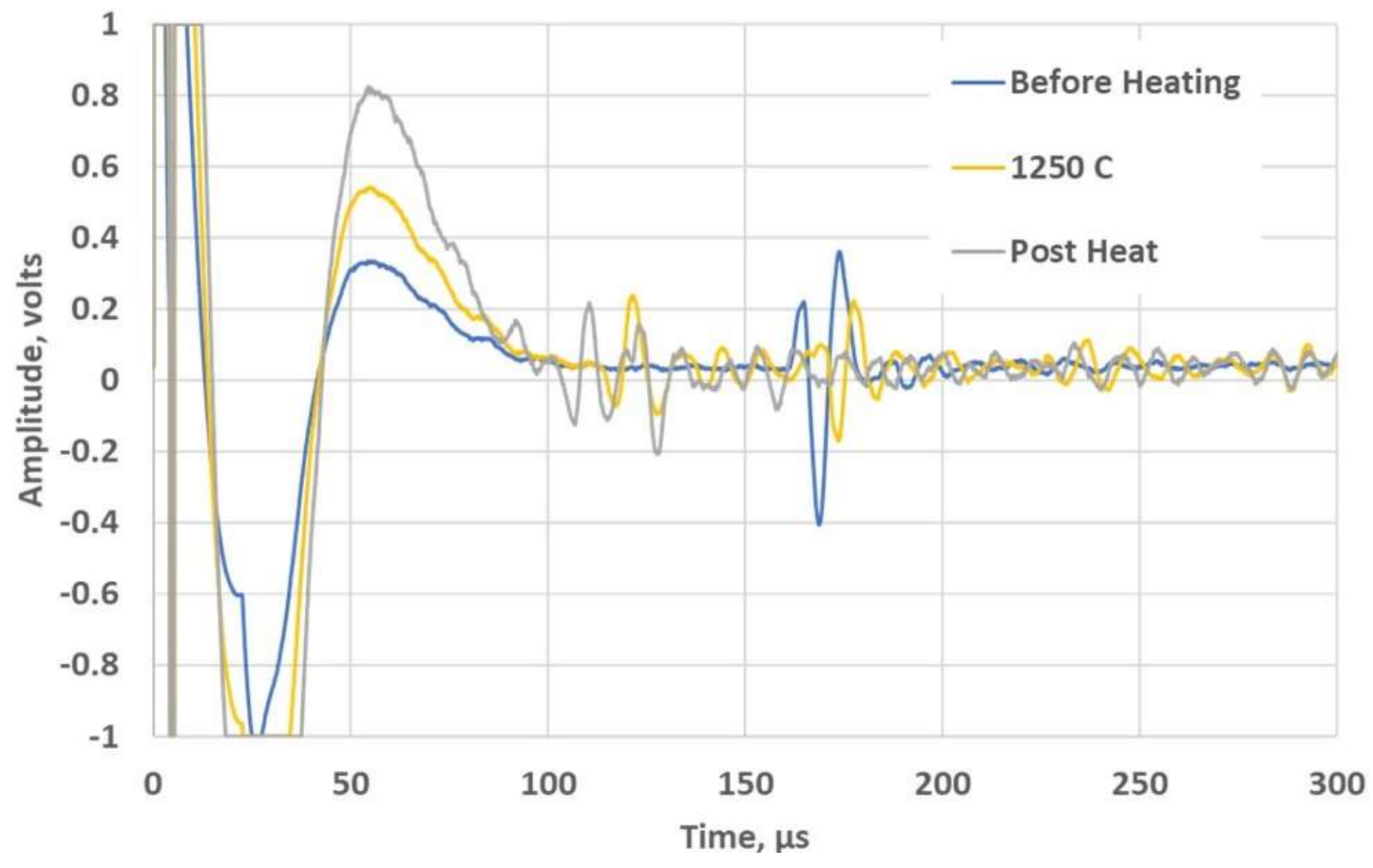

Figure 16. Waveforms recorded for the reference (i.e., no stand-off) Mo UT with an Nb sheath. 
Figure 17 shows waveforms collected at various temperatures for the Mo/Nb UT with the $\mathrm{W}-5 \% \mathrm{Re}$ coil stand-off. Rapid onset of sticking was observed at $1650^{\circ} \mathrm{C}$. This was not the case for the similarly fabricated Zircaloy-4 UT, likely because of the large discrepancy in melting temperatures, as well as the relatively low test temperatures. As the Mo/Nb UT was tested to higher temperatures and fabricated from different refractory metals, the potential for diffusion bonding was much higher. As such, the coil-based stand-off may only be useful at relatively low temperatures.

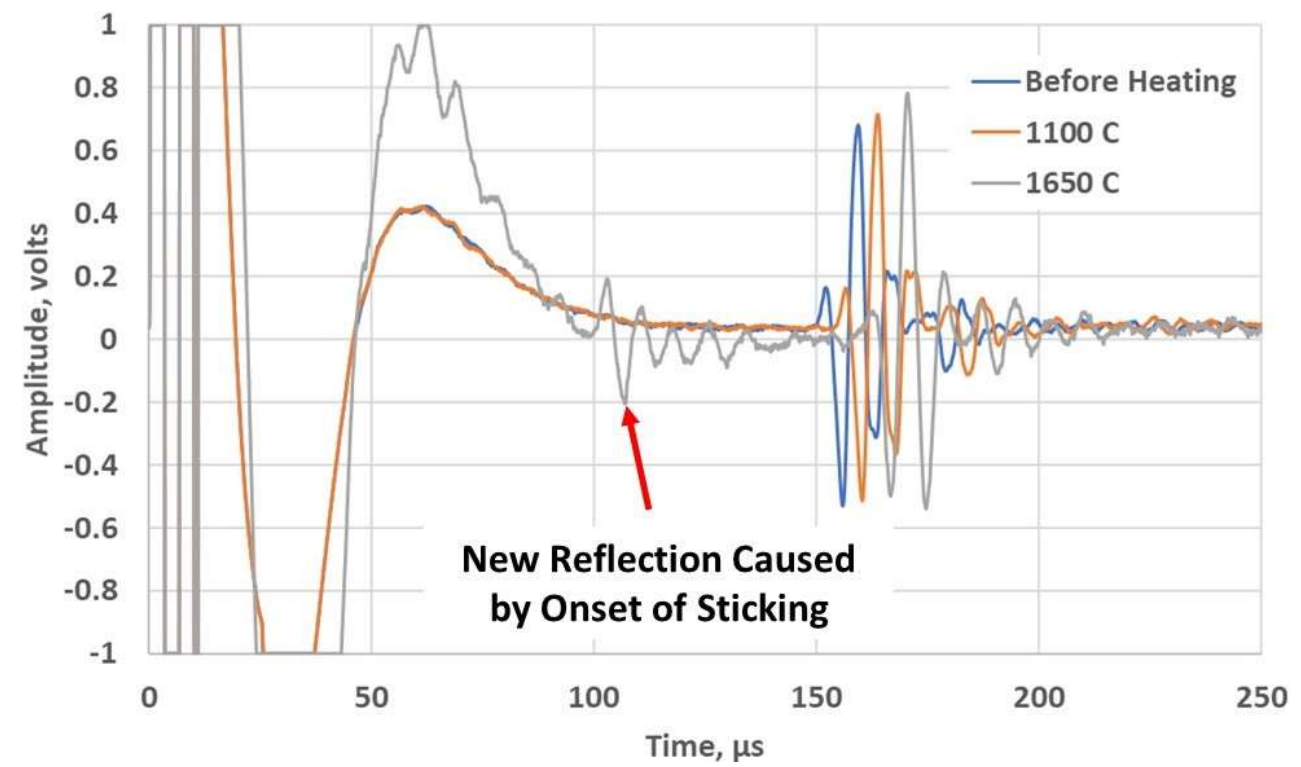

Figure 17. Waveforms recorded for the Mo UT with an Nb sheath and W-5\% Re coil stand-off, showing apparent onset of sticking at $1650^{\circ} \mathrm{C}$.

Figure 18 shows waveforms collected at various temperatures for the $\mathrm{Mo} / \mathrm{Nb} \mathrm{UT}$ with alumina tube spacers. The same lead-in noise observed for the Zircaloy-4 UT with alumina spacers is once again evident, but the onset of sticking between the waveguide and the alumina was observed at $1900^{\circ} \mathrm{C}$.

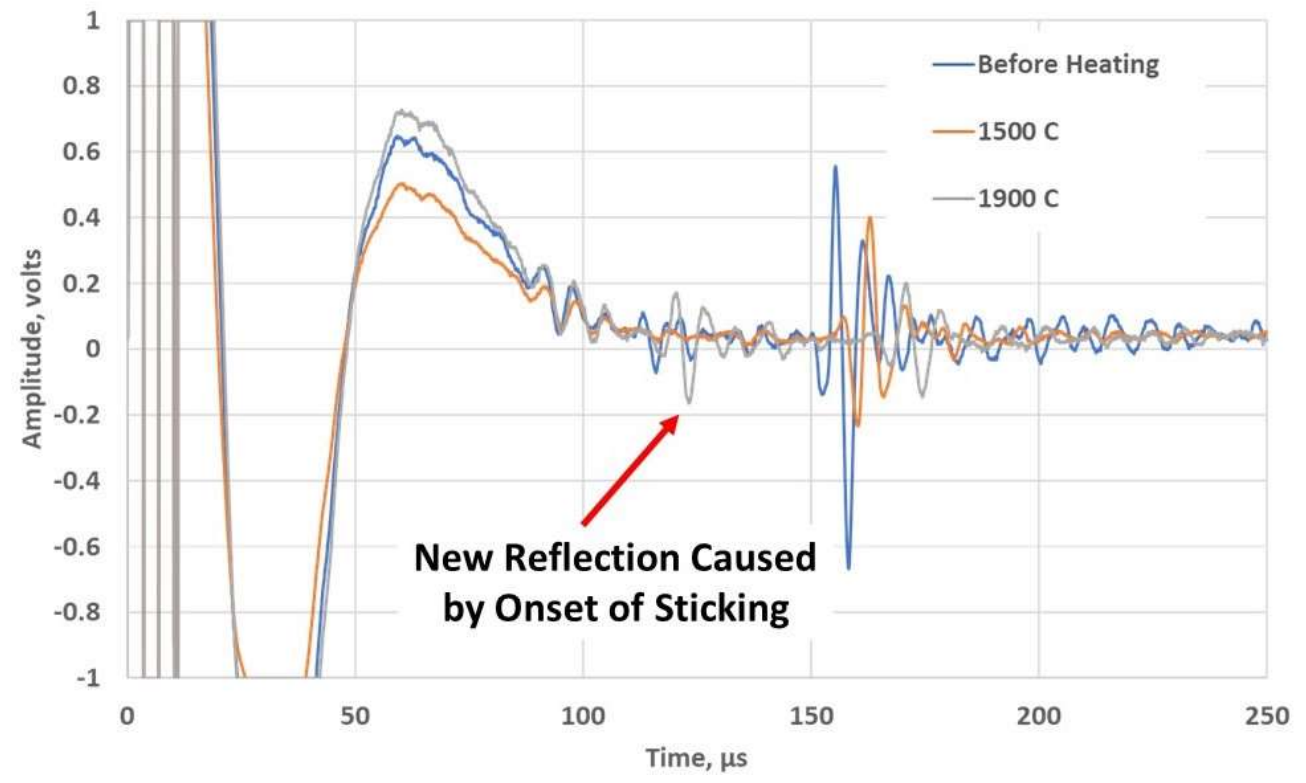

Figure 18. Waveforms recorded for the Mo UT with an $\mathrm{Nb}$ sheath and alumina tube stand-offs, showing apparent onset of sticking at $1900^{\circ} \mathrm{C}$. 
The final group of prototypes were fabricated with Mo waveguides and Mo sheaths. This is considered the standard Idaho National Laboratory design for very high temperature measurements and the targeted application for these anti-sticking methods. For this set, only two UTs were tested, one with a $\mathrm{W}-5 \%$ Re coil stand-off and one with the 3-D-printed alumina spacers.

Figure 19 shows waveforms collected at various temperatures for the Mo/Mo UT with the W-5\% Re coil stand-off. Onset of sticking was observed at $1500^{\circ} \mathrm{C}$, further indicating that the coil-based stand-off may only be useful at relatively low temperatures.

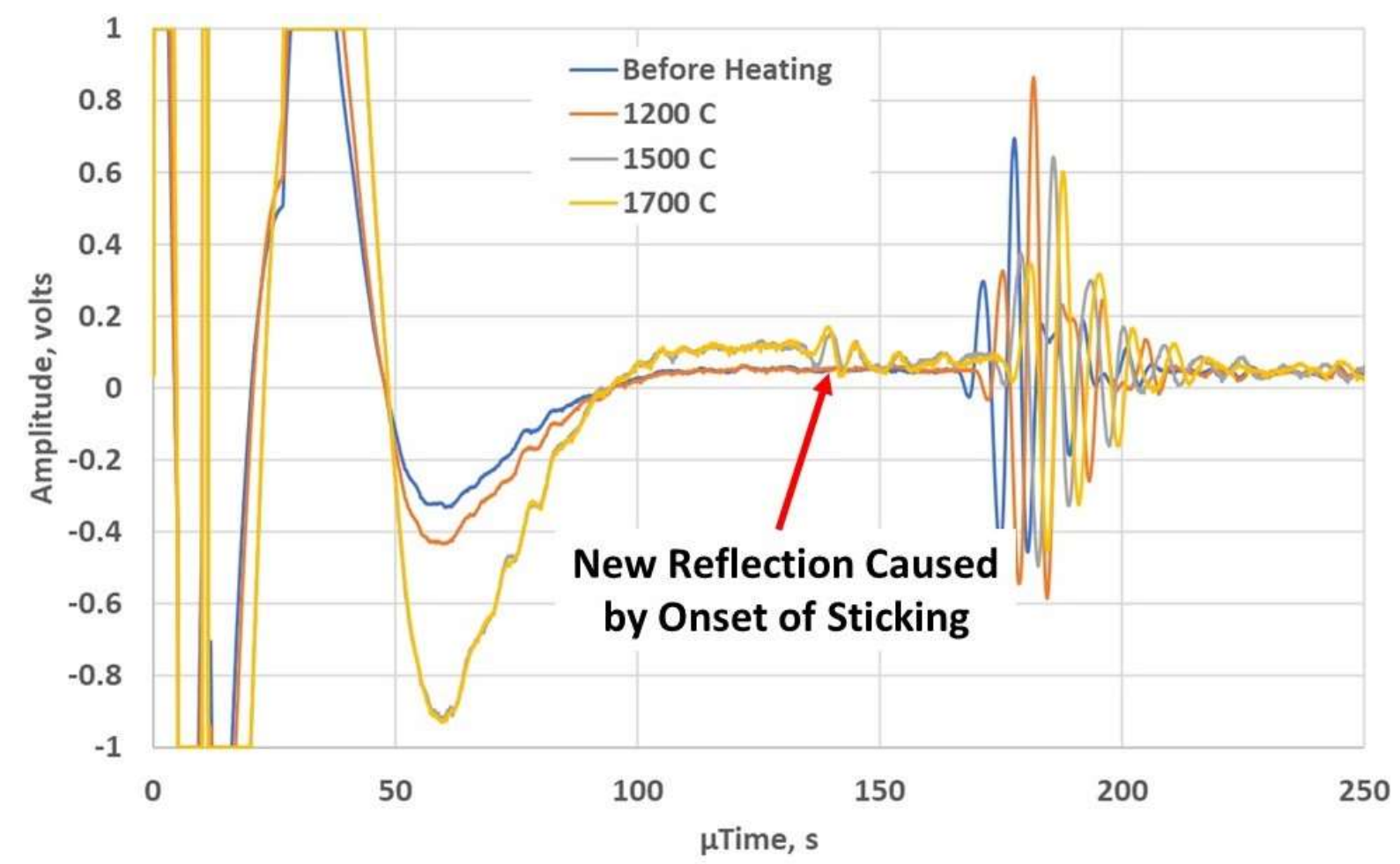

Figure 19. Waveforms recorded for the Mo UT with the Mo sheath and W-5\% Re coil stand-off, showing apparent onset of sticking at $1500^{\circ} \mathrm{C}$.

Figure 20 shows waveforms collected at various temperatures for the Mo/Mo UT with 3-D-printed alumina spacers. The 3-D-printed spacers were only used in the heated portion of the UT, due to the limited number available. The lead-in portion of the UT used alumina tubes, just as with some of the other prototype UTs. As with those prototypes, this meant some additional noise in the recorded signals. The figure shows an obvious increase in the noise observed in the lead-in portion of the signal. This is partly due to the necessary increase in the signal gain to offset attenuation at high temperature, but also results from contact pressure between the waveguide and the alumina tubes, caused by differential thermal expansion. This effect is similar in essence to sticking, but is impermanent and can be circumvented by using alumina tubes with larger inner diameters. Figure 21 gives a closeup view of the signals recorded at 2000 and $2030^{\circ} \mathrm{C}$. The signal change in this case was not caused by diffusion bonding but by the melting of the alumina spacers (at seemingly below the melting point of alumina, though uncertainty in the true temperature of the UT can account for this apparent discrepancy). The spacers, having performed well up to this point, appear the most promising option. 


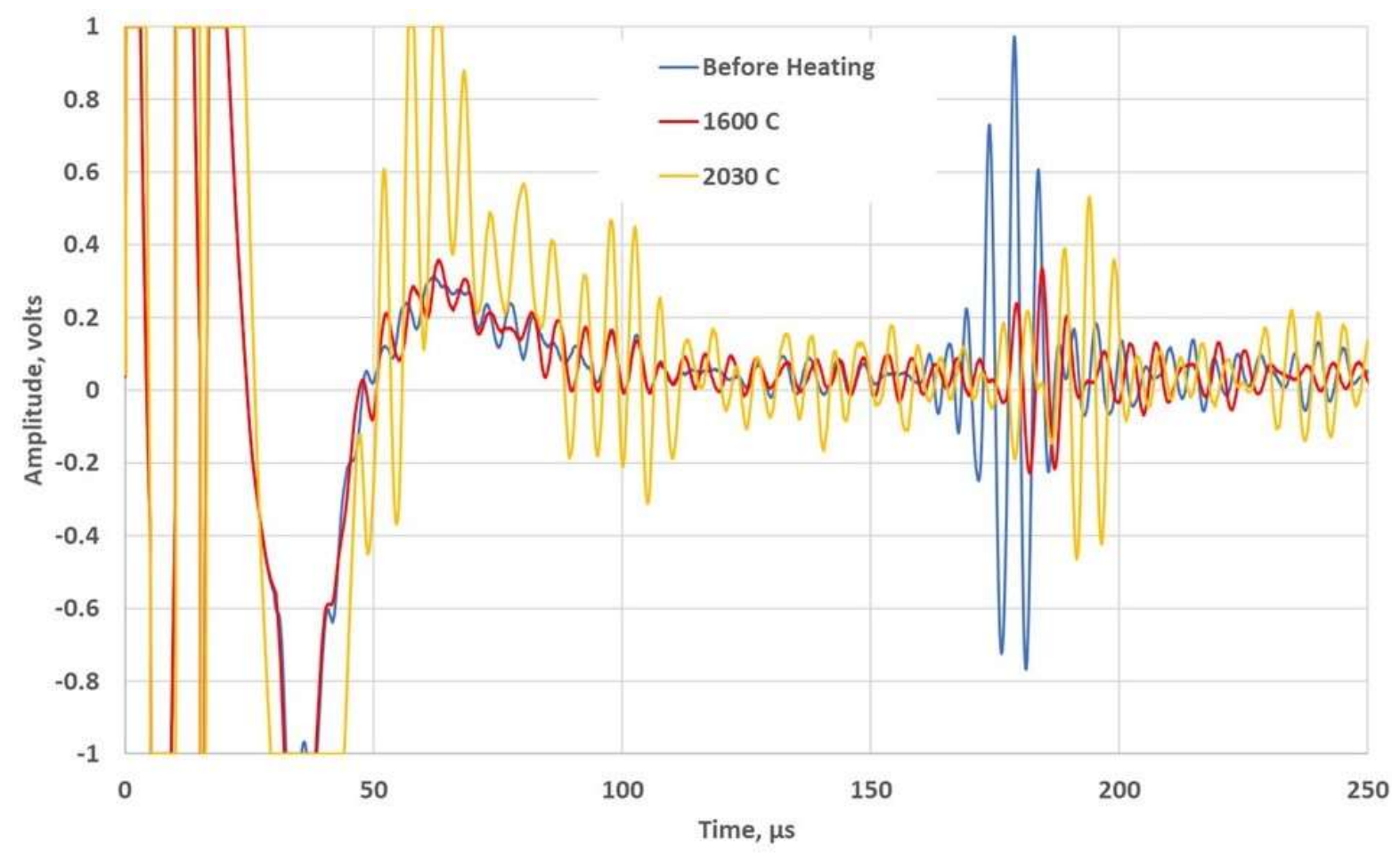

Figure 20. Waveforms recorded for the Mo UT with an Nb sheath and 3-D-printed alumina spacers.

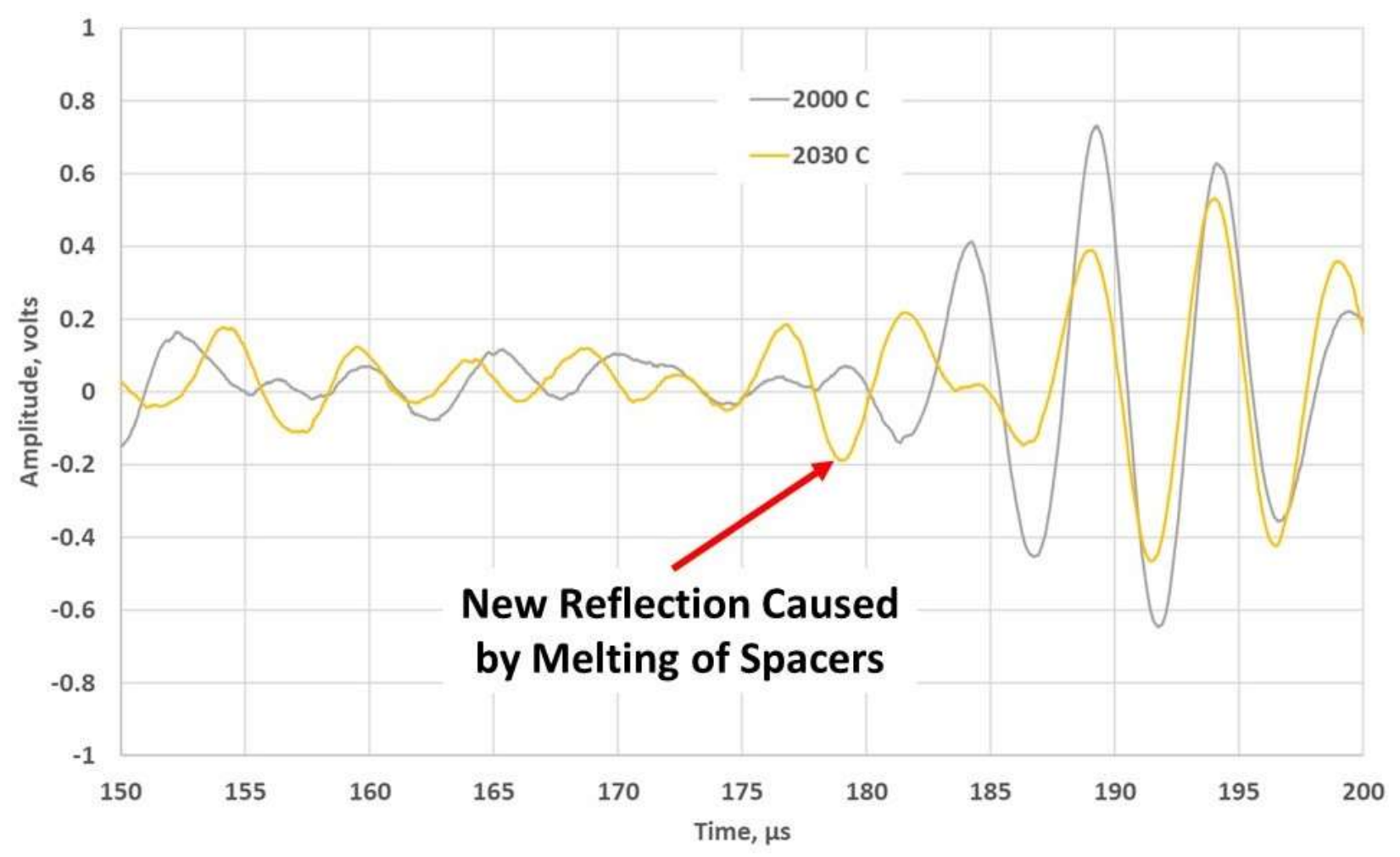

Figure 21. Closeup of waveforms recorded for the Mo UT with an $\mathrm{Nb}$ sheath and 3-D-printed alumina spacers, showing that melting of the spacers occurs at $\sim 2030^{\circ} \mathrm{C}$. 


\section{Summary}

Several different UT configurations were fabricated and then tested under high temperatures in order to identify promising methods for mitigating the "sticking" effect that limits UT performance. Several methods showed promise for low-temperature use (up to at least $1000^{\circ} \mathrm{C}$ ), including the use of a refractory metal coil or alumina tubes to prevent the waveguide from contacting the sheath. The most promising option was 3-D-printed spacers made from alumina. These spacers performed well up until their melting point (i.e., just over $2000^{\circ} \mathrm{C}$ ) was reached. As new ceramic materials become available for 3-D printing, a better alternative to alumina may be found. 
Page intentionally left blank 


\section{References}

1. H. A. Tasman, M. Campana, D. Pel, and J. Richter. 1982. "Ultrasonic Thin-Wire Thermometry for Nuclear Applications," Temperature: Its Measurement and Control in Science and Industry, Vol. 5, Part 2, pp. 1191-1196.

2. R. J. Grossman. 1982. "Ultrasonic-Thermometry Development for In-Situ Measurement of Nuclear-Fuel Temperatures (AWBA Development Program)," KAPL-4160, General Electric Company Knolls Atomic Power Laboratory.

3. M. Laurie, D. Magallon, J. Rempe, S. Wilkins, J. Pierre, C. Marquié, S. Eymery, and R. Morice. 2010. "Ultrasonic High Temperature Sensors: Past Experiments and Prospective for Future Use," International Journal of Thermophysics, 31 (8-9): 1417-1427 Special Issue.

4. E. P. Papdakis, L. C. Lynnworth, D. R. Patch, and E. H. Carnevale. 1972. "Ultrasonic Thermometry in LMFBR Systems," Final Report NYO-3906-13, Panametrics Inc.

5. A. E. Arave, F. E. Panisko, and J. A. Christiansen. 1972. "High-Temperature Ultrasonic Thermometer In-Reactor Fuel Rod Centerline Temperature Test Results," ANCR-1091, Aerojet Nuclear Company.

6. A. E. Arave and J. Buchenauer. 1976. "Use of Tungsten-2\% Thoria Ultrasonic Transmission Line and Sensor to Improve the Performance of High-Temperature Ultrasonic Thermometry," TREENUREG-1021, Idaho National Engineering Laboratory.

7. H. A. Tasman and H. E. Schmidt. 1972. "The Ultrasonic Thermometer-Construction, Application, and Operating Experience," High Temperatures - High Pressures, Vol. 4, pp. 477481.

8. H. A. Tasman, M. Campana, D. Pel, and J. Richter. 1982. "Ultrasonic Thin-Wire Thermometry for Nuclear Applications," Temperature: Its Measurement and Control in Science and Industry, Vol. 5, Part 2, pp. 1191-1196.

9. G. A. Carlson, W. H. Sullivan, and H. G. Plein. 1977. "Application of Ultrasonic Thermometry in LMFBR Safety Research," SAND-77 1157, Sandia Laboratories.

10. G. A. Carlson, W. H. Sullivan, H. G. Plein, and M. Kerley. 1979. "An Ultrasonic Thermometry System for Measuring Very High Temperatures in Reactor Safety Experiments," SAND79-0621, Sandia Laboratories.

11. J. E. Daw and H. K. Woodbury. 2020. "Results of Ultrasonic Thermometer Operational Envelope Testing," INL/EXT-20-59987. 